\title{
Trigger factors associated with migraine headache among Northern Iranian population
}

\author{
Negar Gorjizadeh', Saeed Irian' ${ }^{1}$, Ansar Karimian², Payam Saadat ${ }^{3,4}$ \\ ${ }^{1}$ Department of Cell and Molecular Biology, Faculty of Biological Sciences, \\ Kharazmi University, Tehran, Iran \\ ${ }^{2}$ Cellular and Molecular Biology Research Center, Health Research Institute, \\ Babol University of Medical Sciences, Babol, Iran \\ ${ }^{3}$ Mobility Impairment Research Center, Health Research Institute, Babol University of Medical \\ Sciences, Babol, Iran 4Clinical Research Development Unite of Rouhani Hospital, \\ Babol University of Medical Sciences, Babol, Iran
}

\begin{abstract}
Background. Migraine is the most common neurological disorder associated with a wide range of psychiatric comorbidities. It is therefore regarded as a major global health problem due to its high prevalence. Here we investigated the factors associated with migraine among an Iranian population.

Methods. This investigation included a cross-sectional study consisting of 270 migraine patients. Initially, a questionnaire was designed based on demographic information and headache characteristics. SPSS analyzed the collected data, and chi-square and logistic regression were used to evaluate the clinical data.

Results. Our findings revealed that many migraine patients are experiencing multiple trigger factors, with stressful life events being the most common in both genders and migraine subtypes. The incidence of migraine was higher in women than in men. Among the trigger factors leading to the intensification of migraine attacks, stress, sleep changes, and bright lights were the most common and important causes of headache, followed by tiredness and weather change disturbance.

Conclusions. Considering the contradictory reports on the effect of trigger factors on migraine, further studies are needed to be performed. Due to the significance of the socio-economic impact of migraine on patient's quality of life, strategies for managing these factors should be effectively implemented to improve the community's health.
\end{abstract}

Keywords: headache, migraine disorders, symptoms, trigger factors

\section{INTRODUCTION}

Migraine is the most common primary headache disorder with episodic to chronic form demonstration (1). The headache disorder is characterized by unilateral, pulsating, recurrent attacks with moderate to severe pain intensity. Typically, symptoms linked include nausea, vomiting, photophobia, phonophobia, often leading to attacks that last 4-72 hours, and intensified by routine physical activity (2-4). The association between the prevalence of migraines and the socioeconomic status (SES) is unknown; however, based on clinical studies (5), it results in a significant disability with an enormous socioeconomic burden in addition to negatively affecting the person's daily life, job performance and social activities, while depending on the level of severity, it can substantially impair quality of life $(6,7)$. Migraine is the second headache disorder after tension-type headaches, estimated to affect approximately $15-18 \%$ of the general population $(8,9)$. The prevalence is highly dependent on age and gender with more women (15-18\%) being affected than men $(6 \%)(10,11)$. According to epidemiological studies conducted in Asian countries, the prevalence of migraine has ranged from $8.4 \%$ to $12.7 \%$ (12). Some epidemio- 
logical studies have shown that variables including, age, sex, premenstrual period, menstruation, sleep disorders, stress, skipping meals, level of education, income, climate, geographic region, nutrition, genetics, and environment affect migraine headaches to different degrees (13-16). Studies have shown that stress and other trigger factors can be closely associated with migraine attacks in susceptible patients, with anxiety affecting the severity and threshold of incidence and frequency of headaches $(16,17)$. The links between food items and migraine headaches are complicated; however, the review of clinical scales implicate dietary triggers and the chemical constituent being involved in the mechanism of migraine attacks, affecting migraine's pathophysiology at one or more phases of the migraine. Several different known migrainous triggers could influence the cerebral cortex, trigeminal nerve, brainstem trigeminal nuclei, thalamus, and brainstem or limbic pathways $(17,18)$.

Before puberty, the prevalence of migraine is more frequently in boys than in girls, but after puberty, incidence and prevalence of headaches increase more quickly in girls than in boys, thence the prevalence increases in both genders by almost the age of 40 years, and then decreases $(5,19)$. In many women with migraines, the menstrual cycle and stress are the main factors for migraine headaches. Studies have suggested that hormonal fluctuations, especially those of estrogen-related, are with migraines (20). Several studies on the factors affecting the exacerbation or prevalence of migraine attacks have been reported, with many factors not yet fully understood. Despite advances in the prevention and drug treatment of migraine, recognition of trigger factors, while remaining obscure, would provide an essential element for a successful clinical approach for headache patients, since avoiding such triggers reduces the severity and frequency of attacks are expected $(16,21)$. According to a study in 2017 in Iran, the most common factors exacerbating migraine headaches included stress, bright lights, loud noise, fatigue, and overheating (22).

Epidemiological studies on the effect of headaches can help improve patient care and assess disease and correct classification. Due to different geographical distribution and different socio-cul- tural characteristics, the importance of epidemiological studies becomes apparent. This epidemiological study's main purpose was to determine the associated factors of migraine headache, symptoms, and risk factors for disease progression of migraine in a northern Iranian population in a more comprehensive manner, with the hope of evaluating the existing conditions for future therapeutic interventions.

\section{METHODS}

\section{Subjects}

This study is of a cross-sectional type consisting of 270 migraine patients. From the patients referred to the Ayatollah Rouhani Hospital clinic in Babol-Iran, we received written informed consent to perform this study between October 2018 and December 2019. The diagnosis of migraine was according to the International Classification of Headache Society. Study inclusion criteria included patients referred to Ayatollah Rouhani Hospital, over the age of 16 and below 70-years-old, desire to participate in the study, lack of concomitant underlying diseases, and the exclusion criterion was an inadequate response to all the questionnaire objects. Also, we confirmed in interviews that migraine patients had no experience of medication overuse. For less than 12 months, patients with a headache disorder, with a primary or secondary headache, especially headache due to medication overuse, and severe psychiatric disease were excluded. The Ethics Committee approved the study protocol of the Kharazmi University, Tehran, Iran.

\section{Study questionnaire}

The method of data collection was the questionnaire. Questionnaires prepared for this study contained demographic information (age, gender, family history), headache characteristics (duration of symptoms, migraine whit aura, and migraine without aura), characteristics of accompanying symptoms (nausea, vomiting, photophobia, phonophobia), dietary factors (such as chocolate, nuts, tea/coffee, citrus fruits, fatty foods, spicy foods, meat), exertional activities, and potential risk factors for migraine attacks. The questionnaires and interviews were conducted face to face by neurologists and trained investigators. 


\section{Statistical analysis}

The statistical analyses were conducted using SPSS software. Chi-squared test was used to compare the distributions of categorical variables between groups, and logistic regression was used for the evaluation of trigger factors. Odds ratios (OR) adjusted with $95 \%$ confidence intervals (CI) were calculated for trigger factors. $\mathrm{P}$ values $<0.05$ were considered as statistically significant.

\section{RESULTS}

The migraine incidence was higher in females $(92.2 \%)$ than in males $(7.8 \%)$. The study population consisted of 270 patients, including $170 \mathrm{mi}-$ graine without aura (158 females, 12 males), and 100 migraine with aura (91 females, nine males). A majority of the subjects were aged between 30 and 39 years $(32.2 \%)$. Migraine was associated with a family history of migraine $(60 \%)$. The frequency of headache was less than one attack per month in $13.7 \%$ of the participants, once a month is $20.4 \%$, and more than one attack per month in $64.8 \%$ of the participants (Table 1).

TABLE 1. Demographic characteristics of study subjects showing prevalence rates of migraine

\begin{tabular}{|l|l|}
\hline Migraine prevalence rate & Number (\%) \\
\hline Gender & \\
Female & $249(92.2 \%)$ \\
Male & $21(7.8 \%)$ \\
\hline Age group (in years) & \\
$<30$ & $63(23.3 \%)$ \\
$\mathbf{3 0 - 3 9}$ & $87(32.2 \%)$ \\
$\mathbf{4 0 - 4 9}$ & $75(27.8 \%)$ \\
$\mathbf{5 0 - 5 9}$ & $35(13.0 \%)$ \\
$\mathbf{6 0 - 6 9}$ & $10(3.7 \%)$ \\
\hline Family history & \\
Yes & $163(60 \%)$ \\
No & $107(39.6 \%)$ \\
\hline Frequency of headache & \\
Less than one attack per month & $37(13.7 \%)$ \\
Once a month & $55(20.4 \%)$ \\
More than one attack per month & $175(64.4 \%)$ \\
\hline Headache quality & \\
Throbbing & $212(78.5 \%)$ \\
Pressing & $58(21.5 \%)$ \\
\hline Aura & \\
Yes & $100(37 \%)$ \\
No & $170(63.0 \%)$ \\
\hline
\end{tabular}

Pain characteristics included $78.5 \%$ of migraineurs with headache reported as throbbing and $21.5 \%$ as pressing. Demographic characteristics of study subjects are shown in table 1. Among sub- jects suffering from migraine attacks, $46.6 \%$ of patients experienced photophobia symptoms during premonitory migraine phase. Among migraineurs, $37 \%$ experienced the aura phase of headache. Commonly associated symptoms with a headache have shown in figure 1 . None of those mentioned above parameters demonstrated a statistically significant difference between migraine without aura and migraine with aura (Table 2). $64.1 \%$ of migraine patients experienced attacks with visual phenomena, while $36 \%$ experienced attacks with sensory aura. The most common associated symptoms during headache attacks were phonophobia (83.3\%), photophobia (84.1\%) and nausea (73.0\%) (data have not shown).

TABLE 2. Demographic data and clinical characteristics in two study groups

\begin{tabular}{|c|c|c|c|}
\hline \multicolumn{4}{|l|}{ Headache type } \\
\hline & $\begin{array}{l}\text { Migraine } \\
\text { without aura } \\
(\mathrm{N}=170)\end{array}$ & $\begin{array}{l}\text { Migraine } \\
\text { with aura } \\
(\mathrm{N}=100)\end{array}$ & $p$ value \\
\hline \multicolumn{4}{|c|}{ Migraine prevalence rate } \\
\hline $\begin{array}{l}\text { Gender } \\
\text { Female } \\
\text { Male } \\
\end{array}$ & $\begin{array}{l}158(92.2) \\
12(7.1)\end{array}$ & $\begin{array}{l}91(91.0) \\
9(9.0)\end{array}$ & 0.56 \\
\hline $\begin{array}{l}\text { Age group (in years) } \\
<30 \\
30-39 \\
40-49 \\
50-59 \\
60-69\end{array}$ & $\begin{array}{l}39(22.1) \\
51(30.0) \\
48(28.2) \\
25(14.7) \\
7(4.1)\end{array}$ & $\begin{array}{l}24(24.0) \\
36(36.0) \\
27(27.0) \\
10(10.0) \\
3(3.0)\end{array}$ & 0.75 \\
\hline \begin{tabular}{|l|} 
Pain location \\
On one side of head \\
Whole head \\
Back \\
Front \\
Top \\
\end{tabular} & \begin{tabular}{|l}
$68(40.1)$ \\
$64(37.6)$ \\
$4(2.4)$ \\
$20(11.8)$ \\
$14(8.2)$
\end{tabular} & $\begin{array}{l}49(49.0) \\
35(35.0) \\
2(2.0) \\
7(7.0) \\
7(7.0)\end{array}$ & 0.57 \\
\hline \begin{tabular}{|l|} 
Family history \\
Yes \\
No \\
\end{tabular} & $\begin{array}{l}105(61.8) \\
65(38.2)\end{array}$ & $\begin{array}{l}58(58.0) \\
42(42.0)\end{array}$ & 0.54 \\
\hline $\begin{array}{l}\text { Headache quality } \\
\text { Throbbing } \\
\text { Pressing }\end{array}$ & $\begin{array}{l}133(78.8) \\
37(21.8)\end{array}$ & $\begin{array}{l}79(79.0) \\
21(21.0)\end{array}$ & 0.88 \\
\hline
\end{tabular}

According to the individuals' experience, certain food types such as onion (42.6\%), Sour food $(39.3 \%)$, pepper $(31.9 \%)$ and cheese $(15.9 \%)$ intensified migraine headaches. Factors leading to the onset of migraine headaches included cigarette smoke (54\%), stress $(78.0 \%)$, sleep changes (69.6\%), bright lights $(57.8 \%)$, tiredness $(55.6 \%)$ and weather changes (48.5\%) (data not shown). The results on trigger factors and differences between gender types and subgroups of migraine are listed in tables 3 and 4 . The most frequent trigger 


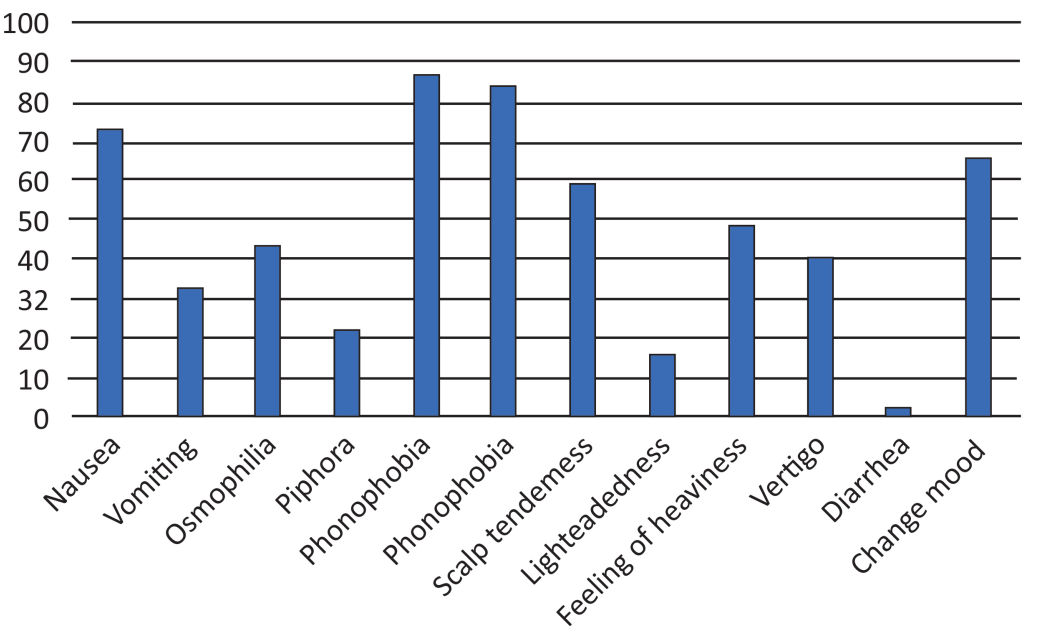

FIGURE 1. Common symptoms associated with headaches (in \%).

factors among female patients with migraine included stress $(79.9 \%)$, sleep changes $(70 \%)$ and excitement (67.1), while those of male patients with migraine were stress $(66 \%)$, fatigue (66\%) and sleep changes $(61 \%)$. A comparison of common triggers factors of headache with gender shown in Figure 2. Considering the P-values ob-

TABLE 3. Trigger factors distribution in genders

\begin{tabular}{|l|l|l|l|}
\hline Triggering factors & \multicolumn{2}{|l|}{ Gender } & p value \\
\hline & Women (\%) & Men (\%) & \\
\hline Food & $14(5.6)$ & 0 & 0.26 \\
\hline Fatty foods & $12(4.8)$ & 0 & 0.303 \\
\hline Chocolate & $41(16.5)$ & $2(9.5)$ & 0.404 \\
\hline Cheese & $10(4)$ & 0 & 0.34 \\
\hline Nuts & $8(3.2)$ & $1(4.8)$ & 0.704 \\
\hline Watermelon & $9(3.6)$ & $1(4.8)$ & 0.92 \\
\hline Citrus fruits & $8(3.2)$ & 0 & 0.404 \\
\hline Tomato & $22(8.8)$ & 0 & 0.15 \\
\hline Fish & $31(12.4)$ & $1(4.8)$ & 0.72 \\
\hline Sausage & $81(32.5)$ & $5(23.8)$ & 0.41 \\
\hline Pepper & $107(43.0)$ & $8(38.1)$ & 0.66 \\
\hline Onion & $9(3.6)$ & $4(19.0)$ & 0.002 \\
\hline Tea/Coffee & $101(40.6)$ & $5(23.8)$ & 0.13 \\
\hline Sour food & $138(55.4)$ & $8(38.1)$ & 0.12 \\
\hline Smoking & $199(79.9)$ & $14(66.7)$ & 0.15 \\
\hline Stress/anxiety & $167(67.1)$ & $8(38.1)$ & 0.08 \\
\hline Excitement & $175(70.3)$ & $13(61.9)$ & 0.42 \\
\hline Sleep changes & $147(59.0)$ & $9(42.9)$ & 0.14 \\
\hline Light & $91(36.5)$ & $4(19.0)$ & 0.10 \\
\hline Physical factors & $123(49.4)$ & $8(38.1)$ & 0.32 \\
\hline Weather changes & $135(54.2)$ & $14(66.7)$ & 0.27 \\
\hline Tiredness & $27(10.8)$ & $2(6.9)$ & 0.85 \\
\hline Humidity & $64(25.7)$ & 0 & 0.008 \\
\hline Irregular meals & $102(41.0)$ & $5(23.8)$ & 0.26 \\
\hline Strong smells & $62(24.9)$ & $1(4.8)$ & 0.03 \\
\hline Sexual activity & $143(57.4)$ & $\mathrm{NA}$ & $\mathrm{NA}$ \\
\hline Menstruation & & & \\
\hline A not app & & \\
\hline & & & \\
\hline
\end{tabular}

NA not applicable
TABLE 4. Comparison of trigger factors frequencies among migraine patients without aura and with aura

\begin{tabular}{|l|l|l|l|}
\hline \multirow{2}{*}{ Triggering factors } & \multicolumn{2}{|c|}{ Headache type } & \multirow{2}{*}{ p value } \\
\cline { 2 - 3 } & $\begin{array}{l}\text { Migraine } \\
\text { without aura (\%) }\end{array}$ & $\begin{array}{l}\text { Migraine } \\
\text { with aura (\%) }\end{array}$ & \\
\hline Fatty foods & $10(5.9)$ & $4(4.0)$ & 0.501 \\
\hline Chocolate & $9(5.3)$ & $3(3.0)$ & 0.0 .33 \\
\hline Cheese & $31(18)$ & $12(12.0)$ & 0.0 .17 \\
\hline Nuts & $6(3.5)$ & $4(4.0)$ & 0.84 \\
\hline Watermelon & $4(2.4)$ & $5(5.0)$ & 0.24 \\
\hline Citrus fruits & $8(4.7)$ & $2(2.0)$ & 0.38 \\
\hline Tomato & $5(2.9)$ & $3(3.0)$ & 0.97 \\
\hline Fish & $14(8.2)$ & $8(8.0)$ & 0.94 \\
\hline Sausage & $22(12.9)$ & $10(10.0)$ & 0.43 \\
\hline Pepper & $60(35.3)$ & $26(26.0)$ & 0.11 \\
\hline Onion & $78(45.9)$ & $37(37.0)$ & 0.15 \\
\hline Tea/Coffee & $10(5.9)$ & $3(3.0)$ & 0.28 \\
\hline Sour food & $75(44.0)$ & $31(31.0)$ & 0.33 \\
\hline Smoking & $94(55.0)$ & $52(52.0)$ & 0.60 \\
\hline Stress/anxiety & $130(76.0)$ & $83(83.3)$ & 0.20 \\
\hline Excitement & $108(63.5)$ & $67(67.0)$ & 0.56 \\
\hline Sleep changes & $114(67.1)$ & $74(74.0)$ & 0.23 \\
\hline Light & $103(60.6)$ & $53(53.0)$ & 0.22 \\
\hline Physical factors & $102(60.0)$ & $73(73.0)$ & 0.03 \\
\hline Weather changes & $98(42.4)$ & $33(33.0)$ & 0.000 \\
\hline Tiredness & $108(63.5)$ & $41(41.0)$ & 0.000 \\
\hline Humidity & $19(11.2)$ & $10(10.0)$ & 0.72 \\
\hline Irregular meals & $46(27.1)$ & $18(18 / 0)$ & 0.09 \\
\hline Strong smells & $72(42.4)$ & $35(35.0)$ & 0.47 \\
\hline Sexual activity & $46(27.1)$ & $17(17.0)$ & 0.05 \\
\hline Menstruation & $88(55.7)$ & $55(60.4)$ & 0.05 \\
\hline P<0.05 was consi) & & \\
\hline & & & \\
\hline
\end{tabular}

$P<0.05$ was considered significant.

tained from the logistic regression test; however, no significant correlation was detected between the trigger factors and intensification of migraine headache (Table 5). 


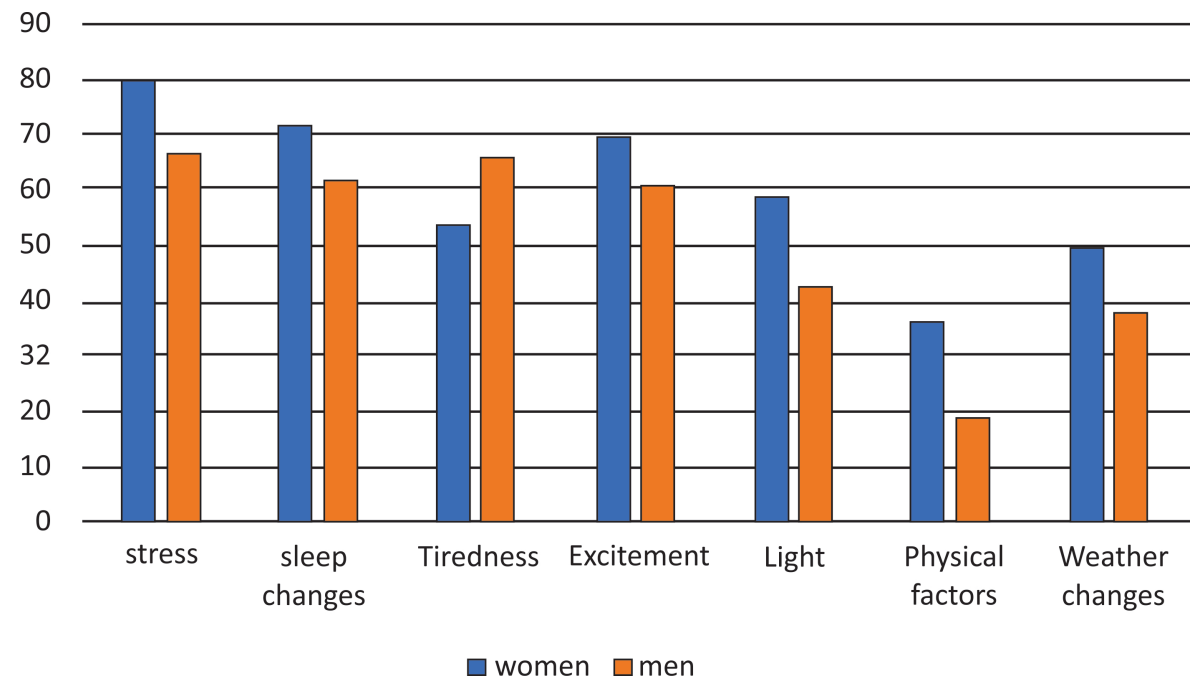

FIGURE 2. A comparison of common triggers factors of headache with gender (in \%).

TABLE 5. Logistic regression analyses of trigger factors of migraine patients

\begin{tabular}{|l|l|l|l|}
\hline Triggering factors & migraine & p value \\
\hline & Non-adjusted OR $^{\mathrm{9} 95}$ \%Cl) & Adjusted OR $^{\mathrm{9} 95}$ \%Cl) & \\
\hline Fatty foods & $0.667(0.203-2.184)$ & $0.924(0.228-3.751)$ & 0.912 \\
\hline Chocolate & $0.553(0.146-2.093)$ & $0.554(0.128-2.393)$ & 0.554 \\
\hline Cheese & $0.611(0.298-1.253)$ & $0.785(0.347-1.773)$ & 0.560 \\
\hline Nuts & $1.139(0.314-4.137)$ & $1.485(0.338-6.514)$ & 0.600 \\
\hline Watermelon & $2.184(0.573-8.331)$ & $2.352(0.563-9.827)$ & 0.241 \\
\hline Citrus fruits & $0.365(0.077-1.725)$ & $0.499(0.088-2.832)$ & 0.432 \\
\hline Tomato & $1.021(0.239-4.365)$ & $1.494(0.266-8.401)$ & 0.649 \\
\hline Fish & $0.969(0.392-2.398)$ & $1.161(0.402-3.353)$ & 0.783 \\
\hline Sausage & $0.665(0.294-1.508)$ & $0.883(0.332-2.350)$ & 0.803 \\
\hline Pepper & $0.644(0.373-1.113)$ & $0.818(0.411-1.629)$ & 0.568 \\
\hline Onion & $0.693(0.418-1.149)$ & $0.881(0.461-1.684)$ & 0.702 \\
\hline Tea/Coffee & $0.495(0.133-1.842)$ & $0.605(0.135-2.701)$ & 0.510 \\
\hline Sour food & $0.569(0.338-0.958)$ & $0.681(0.363-1.278)$ & 0.231 \\
\hline Smoking & $0.876(0.534-1.437)$ & $1.009(0.566-1.800)$ & 0.975 \\
\hline Stress/anxiety & $1.502(0.799-2.823)$ & $1.723(0.849-3.497)$ & 0.132 \\
\hline Excitement & $1.166(0.692-1.962)$ & $1.269(0.690-2.332)$ & 0.444 \\
\hline Sleep changes & $1.398(0.807-2.422)$ & $1.598(0.873-2.923)$ & 0.129 \\
\hline Light & $0.734(0.445-1.208)$ & $0.692(0.387-1.236)$ & 0.213 \\
\hline Physical factors & $0.744(0.440-1.258)$ & $0.850(0.455-1.588)$ & 0.611 \\
\hline Weather changes & $0.852(0.519-1.397)$ & $0.837(0.484-1.448)$ & 0.525 \\
\hline Tiredness & $1.098(0.667-1.806)$ & $1.099(0.626-1.928)$ & 0.743 \\
\hline Humidity & $1.438(0.661-3.130)$ & $1.797(0.746-4.329)$ & 0.192 \\
\hline Irregular meals & $0.785(0.434-1.420)$ & $0.830(0.425-1.618)$ & 0.584 \\
\hline Strong smells & $0.766(0.460-1.274)$ & $0.754(0.424-1.339)$ & 0.335 \\
\hline Sexual activity & $0.598(0.242-1.478)$ & $0.660(0.243-1.794)$ & 0.415 \\
\hline
\end{tabular}

a Logistic regression model, non-adjusted.

$b$ Logistic regression model, adjusted.

$P<0.05$ was considered significant.

\section{DISCUSSION}

Migraine, as the most common brain disorder, appears to be associated with neurological and systemic symptoms. Despite a lack of knowledge on migraine's pathogenesis, a great deal of evidence suggests both genetic and environmental factors, such as hormonal fluctuations, fatigue, stress, meteorological changes, and diet, modulating the threshold of migraine that precedes and evokes a migraine attack $(23,24)$. 
Following an investigation of the related factors of migraine headaches in an Iranian population, it was shown that the incidence of migraine was higher in women than in men, suggesting that migraines in women may be related to the role of female hormones in the development of migraine headaches. It has been reported that with decreasing estrogen levels migraine attacks increase and vice versa (25). Menstruation is the most critical risk factor for the occurrence and persistence of headaches and migraines, with nearly $50 \%$ of women reporting menstruation as a potential migraine trigger. In the present study, hormonal triggers such as menstruation affected individuals differently in patients with aura and without aura, indicating that that migraine headache is a fairly common physical condition in Iran, negatively affecting life quality. Among migraine patients, 37\% were diagnosed as having migraine with aura, with approximately $50 \%$ of cases showing a close relatedness of family history. Reports on migraine relation to family history include those in Africa with $14.6 \%$, and among dental students in India with a reported rate of $20.1 \%(26,27)$.

Significant association in terms of gender and the presence of a family history of headache and the incidence of migraine in female and male students has also been reported by others (26). The increase in migraine prevalence could be due to stress and unhealthy lifestyle habits such as low physical activity (28). Various studies have shown that the risk of developing headaches is greater in individuals with a family history, smoking habit, sleeping problems, premenstrual period, stressful lifestyle, weather changes, menstruation, hunger etc. $(16,29)$.

In the present research, the most common and most important cause of headache included stress, sleep changes and excitement followed by bright lights, tiredness, and weather change disturbance. Most reports have demonstrated stressful situations as the main trigger of a headache attack $(16,30)$. The present study also shows stressful life events as the commonest trigger in both genders and among migraine subtypes. Considering the relation between sleep changes and headache, Kelman group showed that a relatively shorter sleep duration would lead to increased severity and frequency of migraine attacks (31). At the same time, our results demonstrated an association between physical activity and fatigue in recurrent headaches without aura and aura. Conservative management of both factors may be more effective in preventing headaches (32).

Nearly one-half of the subjects with migraine (44.65\%) in the present study believed that spending a long time outside under the sunlight and being exposed to extreme heat made their headaches worse, indicating the role of weather changes as trigger factors, as demonstrated by others $(16,33)$. Although the effect of food factors intensifying migraine headache has been reported by some authors (34), no such relation was detected in the present study (16). Such discrepancies may be explained by existing differences between population's social habits and culture. Investigating the role of diet factors in migraines can be complicated, as various triggers and variables may alter the pain threshold in the individual (17). Dietary intervention in disease contains many components that may interact with various genes in several different ways. If any, interventions to modify targeted diet may lead to the replacement of a proper diet with medication (23). Avoiding foods that are effective in the intensification of migraine headaches could help relieve pain, headache duration, and the number of migraine attacks (22). Considering that by reducing stress in the workplace and stressful life events, one can relieve migraine headaches to some extent, it is thus possible to reduce the frequency and severity of migraine attacks by informing migraine patients of the factors affecting their occurrence migraine attacks.

\section{CONCLUSIONS}

In conclusion, the epidemiological data on the type and quality of headache, family history, related factors and intensifying factors of migraine headaches were obtained. Socio-economic impacts of migraine on the quality of life of patients and society are significant. To improve the health of the community, strategies for managing these factors should be effectively implemented. Also, studies on the prevention, reduction, and control of factors affecting migraine headaches with regard to reinforcing factors can help improve the health of the communi- 
ty. Considering the contradictory reports on the involvement of different migraine trigger factors, it is necessary to conduct studies aimed at defining the effect of trigger factors on the process of migraines in a more accurate manner.

\section{REFERENCES}

1. Ong JJY, Wei DY, Goadsby PJ. Recent Advances in Pharmacotherapy for Migraine Prevention: From Pathophysiology to New Drugs. Drugs. 2018 Mar;78(4):411-437.

2. Andreeva VA, Galan P, Julia C, Fezeu L, Hercberg S, Kesse-Guyot E. A systematic literature review of observational studies of the bidirectional association between metabolic syndrome and migraine. Diabetes Metab. 2019 Jan;45(1):11-18.

3. Ascaso FJ, Marco S, Mateo J, Martínez M, Esteban O, Grzybowski A. Optical Coherence Tomography in Patients with Chronic Migraine: Literature Review and Update. Front Neurol. 2017 Dec 13;8:684.

4. Headache Classification Committee of the International Headache Society (IHS). The International Classification of Headache Disorders, 3rd edition (beta version). Cephalalgia. 2013 Jul;33(9):629-808.

5. Lipton RB, Bigal ME. The epidemiology of migraine. Am J Med. 2005 Mar;118 Suppl 1:3S-10S.

6. Stuart S, Maher BH, Sutherland H, Benton M, Rodriguez A, Lea RA, Haupt LM, Griffiths LR. Genetic variation in cytokine-related genes and migraine susceptibility. Twin Res Hum Genet. 2013 Dec;16(6):1079-86.

7. Xie W, Li R, He M, Cui F, Sun T, Xiong J, Zhao D, Na W, Liu R, Yu S. Prevalence and risk factors associated with headache amongst medical staff in South China. J Headache Pain. 2020 Jan 14;21(1):5.

8. Wijeratne T, Tang HM, Crewther D, Crewther S. Prevalence of Migraine in the Elderly: A Narrated Review. Neuroepidemiology. 2019;52(1-2):104-110.

9. Goadsby PJ, Holland PR, Martins-Oliveira M, Hoffmann J, Schankin C, Akerman S. Pathophysiology of Migraine: A Disorder of Sensory Processing. Physiol Rev. 2017 Apr;97(2):553-622.

10. Kahriman A, Zhu S. Migraine and Tension-Type Headache. Semin Neurol. 2018 Dec;38(6):608-618.

11. Bahra A. Primary Headache Disorders: Focus on Migraine. Rev Pain. 2011 Dec;5(4):2-11.

12. Wang SJ. Epidemiology of migraine and other types of headache in Asia. Curr Neurol Neurosci Rep. 2003 Mar;3(2):104-8.

13. Bigal ME, Lipton RB, Stewart WF. The epidemiology and impact of migraine. Curr Neurol Neurosci Rep. 2004 Mar;4(2):98-104.

14. Lagman-Bartolome AM, Lay C. Migraine in Women. Neurol Clin. 2019 Nov;37(4):835-845.

15. Birru EM, Abay Z, Abdelwuhab M, Basazn A, Sirak B, Teni FS. Management of headache and associated factors among undergraduate medicine and health science students of University of Gondar, North West Ethiopia. J Headache Pain. 2016;17:56.

16. Iliopoulos P, Damigos D, Kerezoudi E, Limpitaki G, Xifaras M, Skiada D, Tsagkovits A, Skapinakis P. Trigger factors in primary headaches subtypes: a cross-sectional study from a tertiary centre in Greece. BMC Res Notes. 2015 Sep 1;8:393.

17. Millichap JG, Yee MM. The diet factor in pediatric and adolescent migraine. Pediatr Neurol. 2003 Jan;28(1):9-15.

18. De Simone R, Ranieri A, Montella S, Bonavita V. Cortical spreading depression and central pain networks in trigeminal nuclei modulation: time for an integrated migraine pathogenesis perspective. Neurol Sci. 2013 May;34 Suppl 1:S51-5.

19. Jeong YJ, Lee YT, Lee IG, Han JY. Primary headaches in children and adolescents - experiences at a single headache center in Korea. BMC Neurol. 2018 May 21;18(1):70.

\section{Acknowledgements}

We thank the Clinical Research Development Unit of Rouhani Hospital for assistance in manuscript submission and references arrangement.

\section{Conflict of interest: none declared} Financial support: none declared

20. Parashar R, Bhalla P, Rai NK, Pakhare A, Babbar R. Migraine: is it related to hormonal disturbances or stress? Int J Womens Health. 2014 Oct 24;6:921-5

21. World Health Organization, 2006. Neurological disorders: public health challenges. Available at: https://apps.who.int/iris/ handle/10665/43605.

22. Zarea K, Rahmani M, Hassani F, Hakima A. Epidemiology and associated factors of migraine headache among iranian medical students: A descriptive-analytical study. Clinical Epidemiology and Global Health 2018 Sep;6(3):109-114.

23. Fila M, Chojnacki C, Chojnacki J, Blasiak J. Is an „Epigenetic Diet” for Migraines Justified? The Case of Folate and DNA Methylation. Nutrients. 2019 Nov 14;11(11):2763.

24. Ophoff RA, van den Maagdenberg AM, Roon KI, Ferrari MD, Frants RR. The impact of pharmacogenetics for migraine. Eur J Pharmacol. 2001 Feb 9;413(1):1-10.

25. MacGregor EA, Frith A, Ellis J, Aspinall L, Hackshaw A. Incidence of migraine relative to menstrual cycle phases of rising and falling estrogen. Neurology. 2006 Dec 26;67(12):2154-8.

26. Adoukonou T, Houinato D, Kankouan J, Makoutode M, Paraiso M, Tehindrazanarivelo A, Viader F, Preux PM. Migraine among university students in Cotonou (Benin). Headache. 2009 Jun;49(6):887-94.

27. Nandha R, Chhabra MK. Prevalence and clinical characteristics of headache in dental students of a tertiary care teaching dental hospital in Northern India. Int J Basic Clin Pharmacol. 2013; 2(1):51-55.

28. Robberstad L, Dyb G, Hagen K, Stovner LJ, Holmen TL, Zwart JA. An unfavorable lifestyle and recurrent headaches among adolescents: the HUNT study. Neurology. 2010 Aug 24;75(8):712-7.

29. Falavigna A, Teles AR, Velho MC, Vedana VM, Silva RC, Mazzocchin T, Basso M, Braga GL. Prevalence and impact of headache in undergraduate students in Southern Brazil. Arq Neuropsiquiatr. 2010 Dec;68(6):873-7.

30. Gupta R, Bhatia MS. Comparison of clinical characteristics of migraine and tension type headache. Indian J Psychiatry. 2011 Apr;53(2):134-9.

31. Kelman L, Rains JC. Headache and sleep: examination of sleep patterns and complaints in a large clinical sample of migraineurs. Headache. 2005 Jul-Aug;45(7):904-10.

32. Wöber C, Brannath W, Schmidt K, Kapitan M, Rudel E, Wessely P, Wöber-Bingöl C; PAMINA Study Group. Prospective analysis of factors related to migraine attacks: the PAMINA study. Cephalalgia. 2007 Apr;27(4):304-14.

33. Robbins $L$. Precipitating factors in migraine: a retrospective review of 494 patients. Headache. 1994 Apr;34(4):214-6.

34. Avijgan M. What is Migraine? What are the symptoms and treatments? What proportion of people does it affect in Australia? Is it more prevalent amongst young people or old, women or men? Available at: https://www.researchgate.net/publication/269926938_ What_is_Migraine_What_are_the_symptoms_and_treatments What_proportion_of_people_does_it_affect_in_Australia_Is_it_ more_prevalent_amongst_young_people_or_old_women_or_men/ citation/download. 